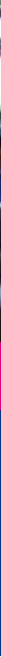

\title{
Favoreciendo el desarrollo local en la Amazonia: lecciones de las iniciativas de manejo forestal comunitario
}

\author{
Gabriel Medina, Benno Pokorny y Bruce Campbell
}

\section{INTRODUCCIÓN}

El avance de la frontera a lo largo de la Amazonia está abriendo nuevas oportunidades a las comunidades tradicionales e indígenas con derechos sobre grandes áreas boscosas. Las oportunidades de obtener beneficios de los productos forestales, especialmente maderables, prometen mejorar los medios de vida en la Amazonia rural - pero sólo si las comunidades locales deciden por si mismas el modo en que sus recursos son explotados.

Típicamente los líderes comunitarios o las familias individualmente negocian contratos informales con las compañías madereras para vender árboles comerciales a cambio de dinero. Sin embargo, las compañías a menudo imponen los términos del contrato y terminan pagando muy poco, a veces incluso nada (Medina, 2004), y las prácticas selvícolas usadas son deficientes y causan grandes daños al bosque (Sabogal et al., 2008). Como resultado, en especial después de varios turnos de corta, los bosques se degradan tanto que las comunidades pierden a menudo buena parte de los recursos no madereros que son esenciales para su modo de vida (Shanley et al., 2002).

Las agencias de desarrollo han actuado ante el problema mediante el apoyo a las comunidades locales para que beneficien la madera por si mismos, en base a planes de manejo creados por expertos externos y autorizados por agencias de los gobiernos centrales. Las ONGs y las agencias gubernamentales, apoyadas por donantes de fondos internacionales, han establecido en la Amazonia los llamados proyectos piloto de manejo forestal comunitario, para así demostrar la viabilidad de sus premisas (Pokorny y Johnson 2008).

La investigación del Proyecto ForLive ${ }^{1}$ financiado por la EU, revela que las iniciativas de manejo comunitario en la Amazonia Boliviana, Peruana y Brasileña no están cumpliendo con las expectativas creadas. Dichas iniciativas a menudo no son compatibles con la realidad local, pues las agencias de desarrollo demandan a las comunidades un manejo del bosque acorde con las prioridades de las propias agencias de desarrollo. Es necesario alcanzar asociaciones de intereses más equitativas si se quiere apoyar a las comunidades en el uso más efectivo de sus recursos forestales.

Hasta el momento, el manejo forestal comunitario tal y como se ha promovido en la Amazonia es menos atractivo para las comunidades locales que incluso los escasos beneficios obtenidos de las compañías madereras. Las agencias de desarrollo, así como las compañías madereras, están obstruyendo los esfuerzos de las comunidades para desarrollar, organizar y aplicar sus propias ideas sobre como usar mejor sus recursos.

\footnotetext{
1 "Manejo forestal por pequeños agricultores en la Amazonía - Una oportunidad para mejorar los medios de vida rurales y la estabilidad de los ecosistemas forestales." (ForLive) (http://www.waldbau.unifreiburg.de/forlive/Project.html)
} 
Este documento pretende establecer la importancia de las asociaciones verdaderamente justas $y$ equitativas en los esquemas locales de manejo forestal. También pretende analizar las circunstancias que favorecen a las comunidades locales en el desarrollo de formas de manejo basadas en sus propios intereses y capacidades, así como identificar cómo las agencias de desarrollo podrían promover el desarrollo autónomo de forma más efectiva.

\section{CASOS ESTUDIADOS}

Este documento está basado en investigaciones llevadas a cabo en cuatro áreas de estudio de Bolivia, Brasil y Perú, todas ellas típicas regiones de frontera caracterizadas por mercados madereros de gran crecimiento (Figura 1). En cada área de estudio fueron seleccionadas dos comunidades: una que negocia sus derechos madereros con empresas madereras y una que recibe apoyo de agencias de desarrollo para adoptar manejo forestal comunitario. Las ocho comunidades fueron estudiadas entre los años 2005 y 2008.

\section{EL ESCASO ATRACTIVO DEL MANEJO FORESTAL COMUNITARIO}

En las cuatro áreas de estudio, casi todas las comunidades (96 por ciento) han negociado de forma informal sus derechos de corta con madereros.

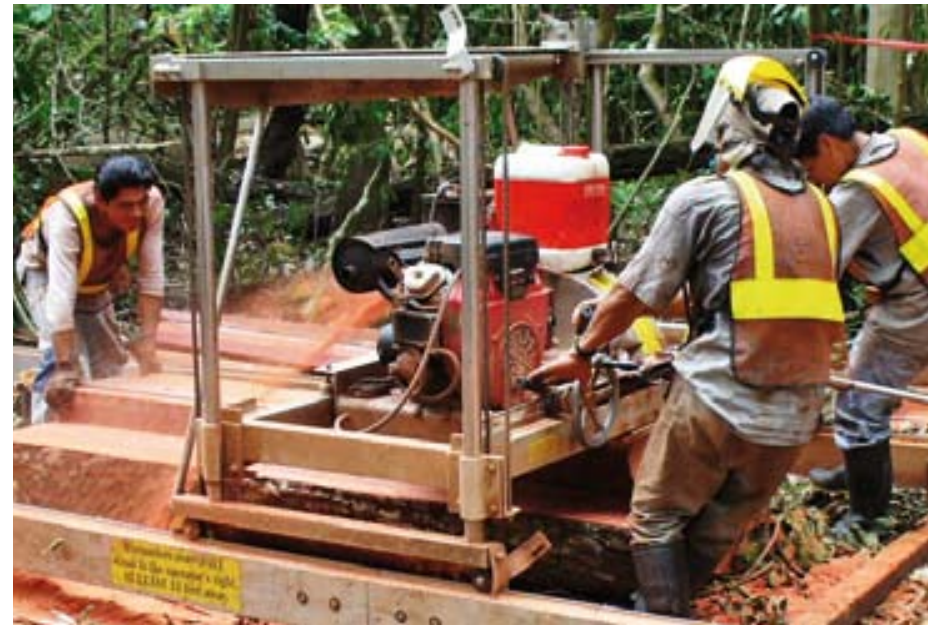

Campesinos indígenas reciben entrenamiento por parte de una ONG sobre el uso de un aserradero portátil en operaciones con certificación forestal. Este tipo de iniciativas piloto apoyan a las comunidades en su manejo forestal, pero las prácticas externamente definidas normalmente son abandonadas una vez que el apoyo concluye (Masisea, Perú).

Por el contrario menos del dos por ciento participó en iniciativas de manejo forestal comunitario (Figura 2), y la mayor parte abandonó las prácticas de manejo forestal una vez que finalizó el apoyo externo. En algunos casos dichas comunidades volvieron a negociar con los madereros.

Los altos costes de implantación de las iniciativas suponen una razón por la cual el manejo forestal comunitario no ha sido adoptado de forma general-estos oscilaron entre US\$25 000 y

Figura 1: Áreas de estudio en la Amazonia Brasileña, Boliviana y Peruana.

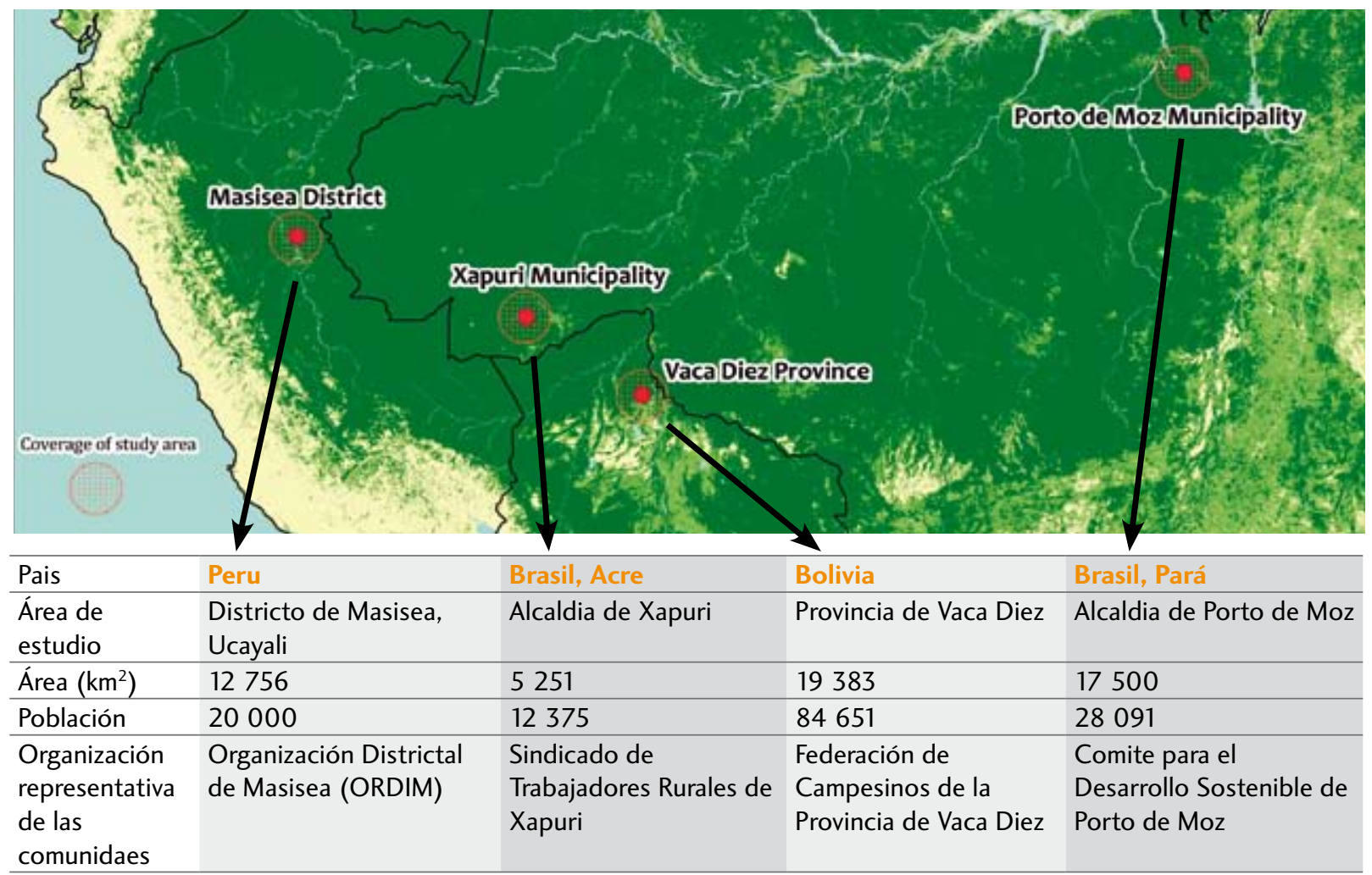


Figura 2: Comunidades que trabajan con agencias de desarrollo y con madereros.

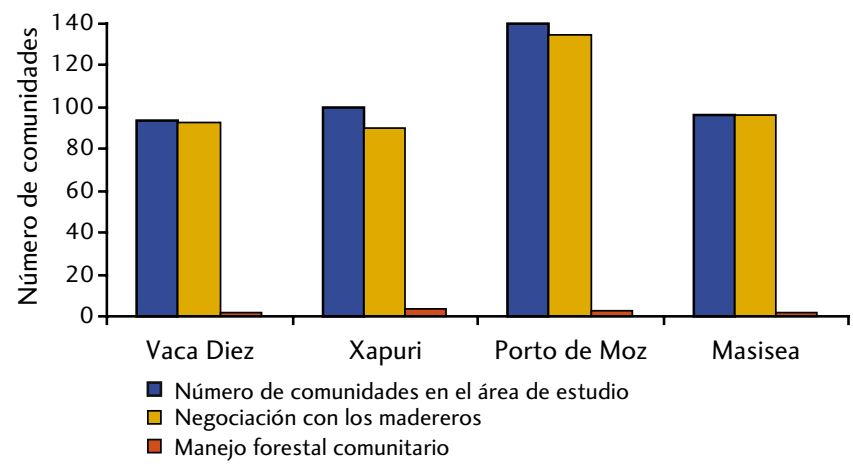

US\$377 000 por comunidad, dependiendo de su área de acción e intensidad. Sin apoyo económico ninguna de las comunidades mostró interés alguno en los esquemas de manejo forestal comunitario.

Otra razón viene dada por los relativamente bajos retornos financieros (Medina \& Pokorny, 2008). Las familias recibieron unos ingresos relativamente importantes por metro cúbico de madera (Tabla 1), pero también invirtieron una cantidad relativamente importante de tiempo en actividades de campo tales como los inventarios forestales y el procesamiento de la madera, además de numerosas actividades de aprendizaje previo. En consecuencia el ingreso medio por persona y día fue de sólo US\$8.69, inclusive con las agencias de desarrollo subvencionando el proceso.

En comparación, las familias que negociaron informalmente con los madereros recibieron muy poco dinero por la madera obtenida, pero aun así obtuvieron un ingreso neto medio de US\$28.14 por persona y día, ya que dedicaron mucho menos tiempo a las actividades selvícolas. Se trata de una cantidad extremadamente atractiva cuando las oportunidades de trabajo son escasas y mal pagadas (Tabla 1).

Los beneficios derivados de la corta de madera y el manejo forestal comunitario no se redistribuyeron de forma uniforme. En el caso del manejo forestal comunitario, sólo un 30 por ciento de las familias en cada comunidad relevante se involucraron y beneficiaron de la madera comercializada, así como de trabajos esporádicos y de la mejora de las vías de acceso a sus propiedades. En cualquier caso las familias que negocian con madereros mencionaron y valoraron positivamente dicha clase de beneficios indirectos.

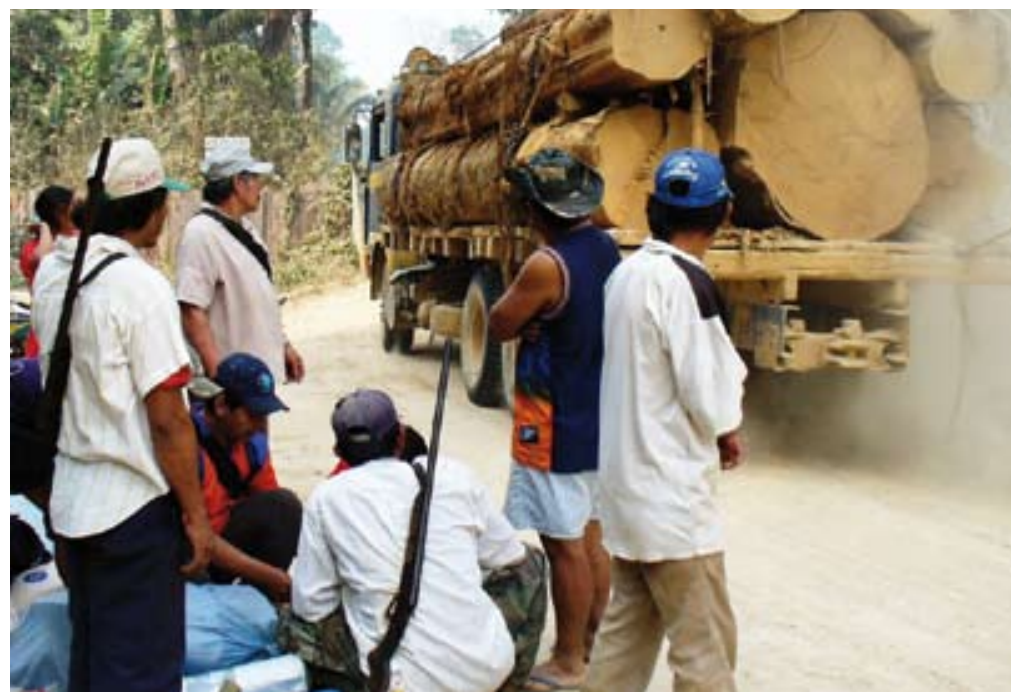

Los miembros de una comunidad observan las trozas extraídas de sus bosques. Los madereros normalmente compran derechos madereros a la comunidad, pero explotan el bosque sin el control de la misma (Vaca Diez, Bolivia).

Tabla 1: Ingresos netos obtenidos por las comunidades de las negociaciones por derechos madereros con las empresas madereras y de las iniciativas de manejo forestal comunitario apoyadas por agencias de desarrollo.

\begin{tabular}{|c|c|c|c|c|c|c|c|c|c|c|}
\hline \multirow[b]{2}{*}{ Estudios de caso } & \multicolumn{5}{|c|}{ Manejo forestal comunitario } & \multicolumn{5}{|c|}{ Negociación con madereros } \\
\hline & $\begin{array}{l}\text { Vaca } \\
\text { Diez }\end{array}$ & Xapuri & $\begin{array}{l}\text { Porto de } \\
\text { Moz }\end{array}$ & Masisea & Media & $\begin{array}{l}\text { Vaca } \\
\text { Diez }\end{array}$ & Xapuri & $\begin{array}{l}\text { Porto de } \\
\text { Moz }\end{array}$ & Masisea & Media \\
\hline$\overline{\text { Beneficios recibidos (US\$) }}$ & 2750 & 7416 & 8977 & 120 & 4815 & 1392 & 14280 & 9520 & 720 & 6478 \\
\hline $\begin{array}{l}\text { Volumen de madera } \\
\text { vendido }\left(\mathrm{m}^{3}\right)\end{array}$ & 550 & 618 & 450 & 9 & 406 & 693 & 6300 & 42000 & 3300 & 13073 \\
\hline Beneficio por $\mathrm{m}^{3}$ (US\$) & 5.00 & 12.00 & 19.95 & 13.33 & 12.57 & 2.01 & 2.27 & 0.23 & 0.22 & 1.18 \\
\hline Número de participantes & 36 & 10 & 10 & 5 & 15 & 20 & 15 & 20 & 76 & 33 \\
\hline $\begin{array}{l}\text { Dias de trabajo por } \\
\text { persona y año }\end{array}$ & 35 & 30 & 135 & 20 & 55,00 & 4 & 25 & 10 & 1 & 10,00 \\
\hline $\begin{array}{l}\text { Ingresos por dia trabajado } \\
\text { por persona (U\$) }\end{array}$ & 2.18 & 24.72 & 6.65 & 1.2 & 8.69 & 17.40 & 38.08 & 47.60 & 9.47 & 28.14 \\
\hline Jornal local por dia (US\$) & 2 & 5 & 5.2 & 1.5 & 3.43 & 2 & 5 & 5.2 & 1.5 & 3.43 \\
\hline
\end{tabular}




\section{EL EFECTO DE LAS \\ INFLUENCIAS EXTERNAS EN LA ORGANIZACIÓN LOCAL}

Las empresas madereras son conocidas por usar su poder para forzar a las comunidades locales a hacer lo que ellas quieren (Medina, 2004). El trabajo de campo indica que las relaciones entre comunidades locales y agencias de desarrollo están igualmente desequilibradas, ya que las comunidades se ven forzadas a adoptar esquemas de manejo forestal externamente definidos. Las agencias de desarrollo imponen sus esquemas de 3 modos distintos:

Primero, las agencias de desarrollo prescriben enteramente la cadena productiva, incluyendo la selección del producto a explotar, las prácticas selvícolas, el mercado objetivo, la estructura organizacional y la estrategia de mercado. Los miembros de las comunidades son entrenados en actividades de campo específicas, tales como inventario forestal y corta, pero la agencia mantiene el control sobre el concepto y las actividades relacionadas. Cuando las comunidades adoptan esquemas concebidos externamente se limitan sus oportunidades para desarrollar sus propias ideas de manejo forestal.

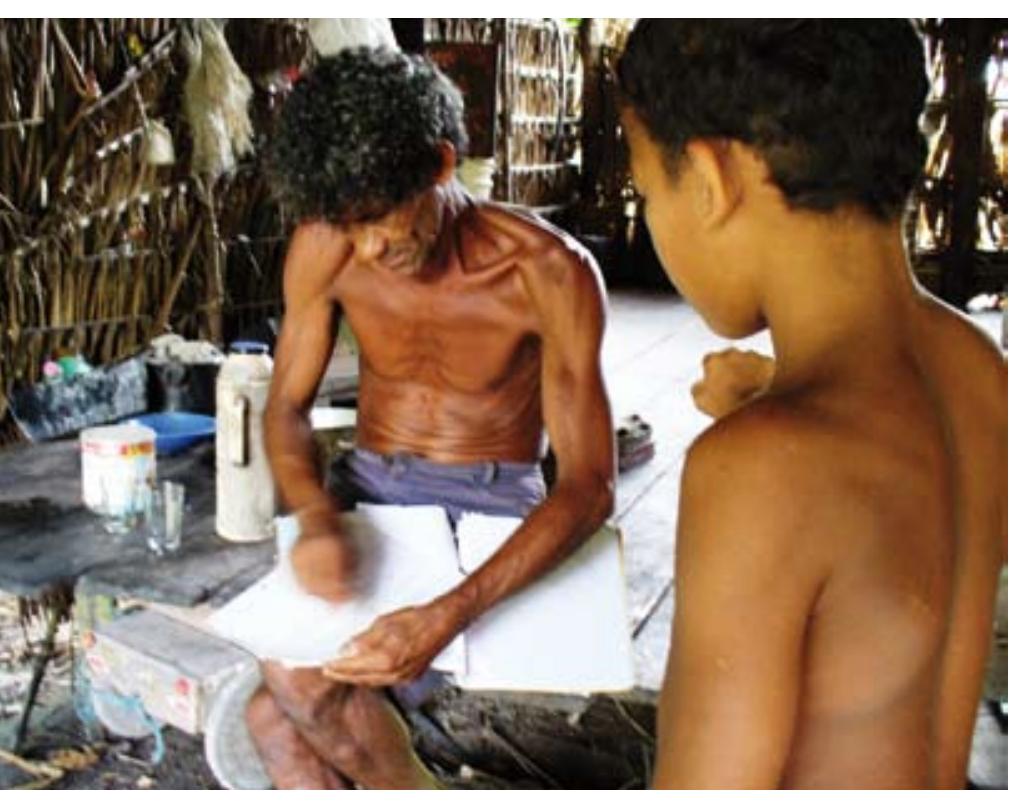

Un miembro de una comunidad escribe una lista de los bienes recibidos de un maderero a cambio de su madera. Las relaciones paternalistas con los agentes foráneos pueden impedir a las comunidades el desarrollo de sus propios modelos de manejo forestal (Porto de Moz, Brasil).
Segundo, las relaciones que las agencias establecen con las comunidades son típicamente paternalistas. Las familias están agradecidas a los madereros y a las agencias de desarrollo, y la mayoría asume las ideas de ambos como si fueran propias. Las relaciones paternalistas perjudican a la organización local al provocar conflictos con el resto de miembros de la comunidad que no están involucrados, y también al crear desconexión entre las diferentes comunidades y sus organizaciones de representación local.

Tercero, con el fin de defender sus conceptos forestales, tanto las agencias de desarrollo como los madereros usan el discurso sobre manejo forestal sostenible. Los madereros argumentan que ellos, al contrario que las comunidades locales, tienen la necesaria capacidad técnica para asegurar un manejo forestal profesional y sostenible. Al mismo tiempo las agencias de desarrollo defienden que la influencia del mercado y las negociaciones con los madereros llevan a las comunidades a sobreexplotar sus recursos a cambio de unos beneficios financieros muy limitados. Por ello argumentan que las comunidades tienen que ser entrenadas para manejar adecuadamente los bosques por si mismos. La idea de que los expertos externos saben mejor lo que hay que hacer domina el debate sobre manejo forestal comunitario, silenciando de forma efectiva las voces propias de la comunidad.

\section{EL POTENCIAL PARA UN DESARROLLO DIRIGIDO LOCALMENTE}

En vista de los escasos beneficios obtenidos de los madereros y de las iniciativas de manejo comunitario, se requieren alternativas. Con ese objetivo este estudio exploró el potencial que las comunidades locales tienen para desarrollar sus propias iniciativas y usar el bosque de acuerdo a sus capacidades e intereses

En contraste con los debates actuales, que se enfocan en una percepción de falta de capacidad de manejo a nivel local, las comunidades en las 4 áreas de estudio han iniciado procesos de regulación del acceso y uso de los recursos locales. Los ejemplos incluyen la demarcación de áreas de aprovechamiento comunal, y el establecimiento de normas para el aprovechamiento de castaña y caucho, así como de acuerdos de pesca (Tabla 2).

Tabla 2: Iniciativas locales de gestión de recursos naturales en las áreas de estudio.

\begin{tabular}{lllll}
\hline & Vaca Diez & Xapuri & Porto de Moz & Masisea \\
\hline Recurso & Árboles de castaña & Caucho y castaña & Pesca y madera & Madera \\
\hline $\begin{array}{l}\text { Sistema de definición } \\
\text { del acceso y uso }\end{array}$ & $\begin{array}{l}\text { Áreas comunales } \\
\text { de recolección de } \\
\text { castaña }\end{array}$ & $\begin{array}{l}\text { Áreas comunales para } \\
\text { el sangrado de los } \\
\text { árboles de caucho }\end{array}$ & $\begin{array}{l}\text { Acuerdos de pesca y } \\
\text { bosques comunales }\end{array}$ & $\begin{array}{l}\text { Territorios y } \\
\text { regulaciones sobre } \\
\text { extracción de madera. }\end{array}$ \\
\hline
\end{tabular}




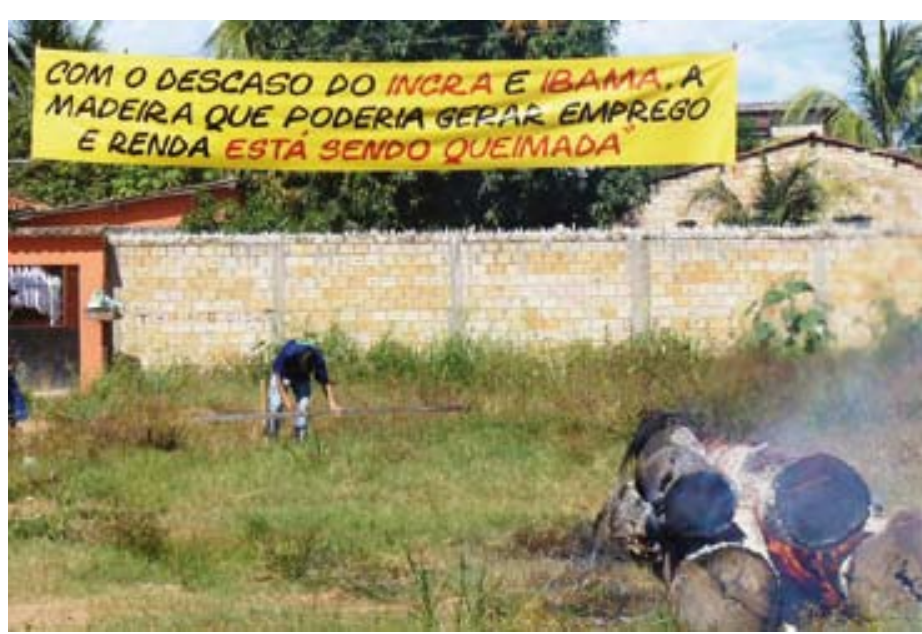

Los madereros anuncian beneficios y trabajo a la población local. Los madereros y las agencias de desarrollo justifican sus perspectivas sobre como las comunidades amazónicas deberían usar sus bosques (Altamira, Brasil).

Para entender mejor las posibilidades de desarrollar esquemas de manejo local, se analizaron las circunstancias bajo las cuales las comunidades: (1) desarrollaron esquemas de manejo de acuerdo a sus intereses y capacidades; (2) fueron capaces de identificar intereses comunes y de organizarse para fortalecer sus perspectivas; y, (3) fueron capaces de que sus visiones fueran reconocidas por la sociedad.

El análisis reveló que los esquemas de manejo local siempre aparecen cuando los actores externos, tales como grandes productores, madereros $y$ pescadores comerciales, llegan a la comunidad y amenazan el acceso de la comunidad a sus propios recursos. En ningún caso dichos sistemas existieron con anterioridad. Los esquemas de manejo local han tenido la necesidad de definir normas para regular el acceso y el uso de los recursos tanto para los actores externos como para las propias familias locales.

En todos los ejemplos exitosos, las comunidades se organizaron para reforzar sus derechos respecto a agentes foráneos con los cuales tenían relacciones distanciadas (en contraste con paternalistas) e incluso relaciones conflictivas. Estas situaciones ocurrieron cuando el sector privado comenzó a explotar los recursos de la comunidad sin negociación previa; en estas circunstancias en particular, las comunidades fueron capaces de identificar sus intereses comunes y de organizarse para resistir ante una amenaza común.

En todas las zonas estudiadas las demandas de las comunidades locales y sus organizaciones representativas recibieron escasa atención en el ámbito político fuera de las comunidades. Los sistemas de manejo de las comunidades solo se dieron a conocer mediante alianzas con socios poderosos, tales como las organizaciones medioambientales.
A cambio de su apoyo, estos socios generalmente requirieron de las comunidades la adaptación de sus demandas iniciales a los intereses, conceptos y argumentos de sus nuevos aliados.

\section{CONCLUSIONES}

Al contrario de lo esperado, las comunidades indígenas y tradicionales no se han beneficiado significativamente de sus recursos madereros cuando estos han sido manejados en el marco de iniciativas de manejo forestal comunitario formalmenteautorizadasyfuertementepromovidas. El enfoque actual tiene limitaciones intrínsecas, tales como los altos costes de implementación, la baja adopción, una viabilidad financiera limitada, y prácticas no sostenibles una vez que se acaba el apoyo externo. Generalmente las comunidades retoman la negociación informal de derechos de corta con los madereros cuando esto ocurre.

La naturaleza limitada de los beneficios se debe básicamente a que las comunidades explotan sus bosques en base a relaciones de dependencia con actores externos, tanto con autenticas agencias de desarrollo como con empresas madereras. Esta dependencia ahoga las iniciativas concebidas localmente.

Las agencias de desarrollo y las empresas madereras fuerzan esquemas de manejo definidos de acuerdo a sus propios intereses y conocimientos, sin considerar adecuadamente los intereses locales, sus prioridades y capacidades. El carácter paternalista de la relación, y el discurso hegemónico sobre manejo sostenible que promueven restringe las posibilidades de una colaboración más exitosa. Las comunidades simplemente se hacen más dependientes de los actores externos, y pierden su capacidad de desarrollar esquemas autogestionados de manejo de recursos.

Los enfoques de autogestión emergen del conocimiento local en respuesta a contextos cambiantes, y dependen menos de aspectos tecnológicos que del control social. Para las comunidades de la frontera amazónica desarrollar sus propios esquemas depende principalmente de establecer relaciones autónomas (en oposición a relaciones de dependencia) con los actores externos.

Una vez que las comunidades locales regulen el acceso y uso de los recursos, tenderán a implementar y asegurar el cumplimiento de dichas regulaciones. Los sistemas locales tienden también a ser más flexibles y preparados para adaptarse a contextos dinámicos, típicos de la Región Amazónica (Muñoz et al., 2007). Las comunidades no dependientes pasan a ser capaces de dirigir su propio desarrollo, reforzando el papel de la gente local en la sociedad, reforzando así también al conjunto de la sociedad. 
Este estudio desvela que las comunidades se vuelven autónomas por si mismas, en vez de serlo a través de esfuerzos externos. Ello no implica quitar importancia a la asistencia externa, pero la colaboración requiere un equilibrio de poder equitativo entre las comunidades locales y los agentes externos, los cuales en caso contrario tienden a dominar debido a sus mayores recursos, cualificación e influencia pública. Con relaciones más equilibradas, las comunidades pueden participar como protagonistas autónomos y beneficiarios de las políticas de desarrollo a favor de los pobres en la región.

\section{RECOMENDACIONES}

Se debe desarrollar un nuevo modelo de apoyo al manejo forestal por parte de las comunidades. El nuevo enfoque debe reconocer que un esquema funcional de manejo forestal comunitario requiere lo siguiente:

- En vez de apoyo externo intensivo a iniciativas piloto, se debe desarrollar un marco de apoyo extensivo, alcanzando a un grupo mayor de comunidades.

- En vez de dar apoyo prescriptivo se debe permitir a las comunidades tener autonomía para desarrollar sus propios conceptos de uso del bosque.

- En vez de centrarse en controlar y dirigir los procesos, debe permitirse la aparición de sistemas regulatorios locales definidos por las comunidades $y$ sus organizaciones representativas.

\section{REFERENCIAS}

Medina, G. 2004. Ocupação cabocla e extrativismo madeireiro no Alto Capim: Estratégias de Reprodução camponesa. Acta Amazônica, 34 (2): 315-324.

Medina, G. \& Pokorny, B. 2008. Avaliação financeira do manejo florestal comunitário. Brasília, IBAMAProManejo, 224p.

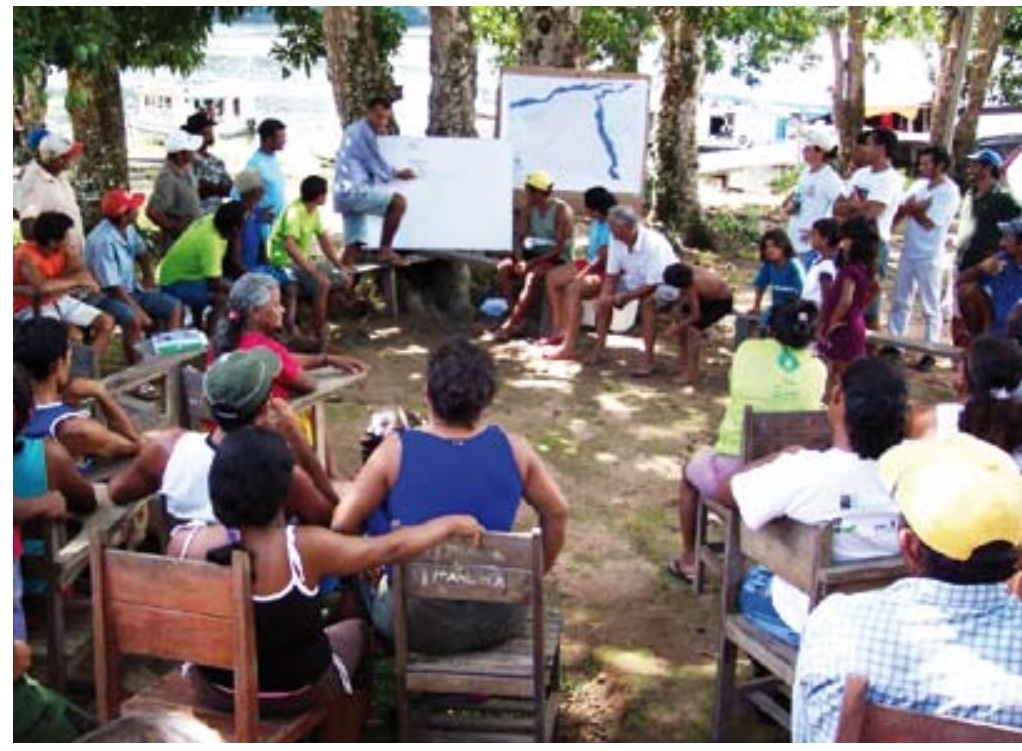

Comunidades vecinas discuten las reglas de un acuerdo pesquero. A lo largo de la Amazonia, las comunidades están desarrollando métodos eficaces para regular el acceso y el uso a los recursos (Porto de Moz, Brasil).

Muñoz, I., Paredes, M. \& Thorp, R. 2007. Group inequalities and the nature and power of collective action: case studies from Peru. World Development, 35, (11), 1929-1946.

Pokorny B. and J. Johnson 2008. Community forestry in the Amazon: The unsolved challenge of forests and the poor. ODI Natural Resource Perspectives 112, 4p.

Sabogal, C., Snook, L., Boscolo, M., Pokorny, B., Quevedo, L., Lentini, M., Colán, V. 2008 Adoção de práticas de manejo florestal sustentável na Amazônia: impulsores e limitantes. Belém: Cifor, $8 \mathrm{p}$.

Shanley, P., Luz, L. \& Swingland, I. 2002. The faint promise of a distant market: A survey of Belém's trade in non-timber forest. Biodiversity and Conservation, 11, 615-636. 